\title{
Экспертиза
}

ВОЛОБОЕВА Юлия Константиновна - специалист Центра изучения китайского языка (195043, Россия, г. Санкт-Петербург, Ново-Ковалево, 12; voloboеva93@таil.ru)

ГОРБАЧЕВ Михаил Валерьевич - доктор политических наук, доцент кафедры российской политики факультета политологии Московского государственного университета им. М.В. Ломоносова (119192, Россия, г. Москва, Ломоносовский пр-кт, 27; ussr-86@таil.ru)

ЯН Мин - координатор культурно-образовательных программ туристического комплекса г. Сианя (710048, КНР, г. Сиань, 101, Джайфанг/101; ауптіт3253454@126.com)

\section{МОДЕЛИ ИДЕНТИФИКАЦИИ ПРОЕКТОВ НОВОГО ШЕЛКОВОГО ПУТИ}

Аннотация. В статье изучаются модели идентификации проектов Нового шелкового пути в Индии, Китае, США, России. В результате проведенного анализа авторы выделяют их цивилизационные, суперконтинентальные, политические версии. Авторы проводят их сопоставление, дают описания их ключевых характеристик. В статье подчеркивается устойчивость и последовательная реализация субъектами проектирования цивилизационных моделей, ставятся под сомнение возможности выполнения в обозримом будущем вариации суперконтинентальных моделей.

Ключевые слова: Великий шелковый путь, Новый шелковый путь, идентификация проектов Нового шелкового пути

$\mathrm{B}^{\mathrm{r}}$ конце XX - начале XXI в. ряд государств, такие как Индия, Китай, Россия, США и др., выступили с инициативами возрождения Шелкового пути. Их проекты получили разные названия, отличались уникальным и многообразным содержанием. Тем не менее проблемы, связанные с их идентификацией, не возникали. Ситуация изменилась, когда страны осуществили переход от концептуальной стадии проектной деятельности к практической. Эта стадия характеризовалась «проектными наложениями», «смешиваниями», «вытеснениями», «поглощениями» и т.п. В результате первоначальные проектные параметры значительно изменились. Цель данной статьи состоит в поиске и выделении моделей идентификации проектов Нового шелкового пути в Индии, Китае, России, США на основе соотнесения практических действий данных стран с их проектными замыслами.

Обращаясь к интерпретации проектных идей КНР, касающихся Нового шелкового пути, необходимо отметить, что в системном виде они стали проявляться в начале 1990-х гг. Так, Китай начал активно строить транспортные пути, которые соединили крупный морской порт Ляньюньгань (побережье Желтого моря) с Хоргосом (граница с Республикой Казахстан). Транспортировка грузов на данном участке сократилась до двух дней, что было рекордно малым показателем для того периода времени. Следующим шагом стал транспортный коридор ТРАСЕКА, который соединил КНР с Европой. Маршрут проходил через Среднюю Азию, Иран, Грузию, Турцию, Румынию, Украину. Реализация транспортной составляющей проекта сопровождалась продвижением его цивилизационных ценностей. В частности, финансировались подпроекты, нацеленные на обмен культурным опытом между народами, участвующими в строительстве транспортной инфраструктуры [Nisimura 2020]. Необходимо отметить, что стремление Китая интенсифицировать культурный обмен с государствами и обществами, вовлеченным в проектную деятельность, носило фрагментарный характер.

Попытку более синхронно продвигать инфраструктурные и цивилизационные инициативы можно было наблюдать в транспортном проекте КазахстанРоссия-Беларусь. Его характеристики казались понятными в начале нулевых 
годов. Однако, несмотря на декларированную цивилизационно-экономическую направленность, на стадии реализации он, так же, как и ТРАСЕКА, трансформировался в сторону типичного экономического проекта. В результате он стал лишь одним из нескольких направлений развития более масштабного цивилизационного проекта - проекта «Новый шелковый путь». Концептуальные основы последнего были озвучены в 2013 г., когда Си Цзиньпинь посетил ряд государств Центральной Азии. В концентрированном виде они имели вид формулы: «Один пояс - один путь». В развернутом виде они предусматривали создание «экономических коридоров вдоль Шелкового пути» 1 , включающих в себя систему современных железных дорог, автомобильных магистралей нового типа, нефтегазовых трубопроводов, авиалиний, направлений морского сообщения» ${ }^{2}$. Также, согласно проектным задумкам, «путь» должен объединить Азию, Европу, Африку, Латинскую Америку - более 60 стран с населением 4,4 млрд чел. В качестве цивилизационной основы подобного объединения провозглашалась «идея создания большой семьи, члены которой будут гармонично сосуществовать друг с другом» 3 .

Мирное сосушествование стран, объединенных идеей «большой семьи», согласно задумкам представителей КНР, будет способствовать эффективному развитию двух типов маршрутов «пути»: сухопутного и морского. Сухопутные транспортные коридоры планируется провести по трем направлениям: северный коридор, проходящий через Казахстан, Россию, Беларусь; южное направление: Южная и Юго-Восточная Азия; центральный транспортный коридор, ориентированный на Азию и Ближний Восток [Тавровский 2017]. В свою очередь, морская часть «пути» (от Южно-Китайского моря до Индийского океана и далее $\left.{ }^{4}\right)$, нацелена на интенсификацию экономических связей Китая со странами Персидского залива и Средиземного моря.

Необходимо отметить, что, в отличие от первоначальных проектных моделей Нового шелкового пути, предлагаемых Китаем, модель «Один пояс - один путь» ориентирована на синхронное решение инфраструктурных и социокультурных задач. Проект позиционируется как экономический и цивилизационный одновременно. Такая идентификация проекта активно поддерживается КНР. Например, Пекин посредством грантовой поддержки активно стимулирует образовательные организации Китая и Центральной Азии, изучающие общую историю народов, которые проживают вдоль Нового шелкового пути [Кузнецова 2017]. В данном контексте директор Института исследований АТР и мировой стратегии КАОН профессор Ли Сянян отмечает, что инициатива экономического пояса Шелкового пути является новым шагом на пути открытости Китая к внешнему миру и формирует основы экономической и цивилизационной дипломатии, которая является новым механизмом взаимодействия, отражающим китайскую философию «дружбы, доверия, взаимной выгоды и терпимости» [Lee 2015: 54].

Так же как и КНР, США начали предлагать различные проектные модели Нового шелкового пути в конце 1980-х - начале 1990-х гг. Они были связаны с интерпретацией центральноазиатских республик, которые ранее входили в советский блок, а также Афганистана, Ирана, Пакистана и Индии в качестве

\footnotetext{
1 Проект «Один пояс, один путь». 2019. Доступ: https://tass.ru/info/4383152 (проверено 24.04.2020).

2 Россия и Китай активизируют работы по проекту «Один пояс - один путь». 2019. Доступ: https:// ria.ru/20191003/1559412278.html (проверено 24.04.2020).

3 Новый китайский папа: Пекин собирается стать ведущей силой в Евразии. 2017. Доступ: https:// ria.ru/20170515/1494297708.html (проверено 24.04.2020).

4 Escobar P. 2019. Welcome to the Indo-Russia maritime Silk Road. - Asia Times. September 5. URL: https://asiatimes.com/2019/09/welcome-to-the-indo-russia-maritime-silk-road/ (accessed 24.04.2020).
} 
единого макрорегиона [Старр 2005]. Согласно проектным построениям американской политической элиты, этот макрорегион было необходимо связать единой транспортной и торговой инфраструктурой [Starr 2009]. В контексте обозначенных идей Азиатский банк развития в 1997 г. выступил со стратегической инициативой центральноазиатского регионального экономического сотрудничества ${ }^{1}$. Программа была нацелена на стимулирование экономического роста посредством реализации крупных инфраструктурных проектов в таких государствах, как Афганистан, Азербайджан, Казахстан, Кыргызстан, Таджикистан, Узбекистан, Монголия. Цивилизационной основой Центральноазиатского регионального экономического сотрудничества выступали концептуальные положения проекта «Великий шелковый путь» и проекта «Большая Центральная Азия» [Тулепбергенова 2009]. В организационных документах Сотрудничества Центральная Азия называлась ключевым пространством, которое обеспечивает связь между различными культурами и экономическими рынками. Идеологи Сотрудничества полагали, что необходимо «преодолеть изолированность региона от мировых рынков, снизить чрезмерную ориентацию экономик стран ЦА на Россию» [Сафранчук 2013: 47].

Идеи, связанные с дальнейшим развитием Сотрудничества, стали главными ориентирами политического турне государственного секретаря США К. Райс по странам Центральной Азии в 2005 г. Однако после его завершения Вашингтон частично скорректировал свое видение Нового шелкового пути. В результате в июле 2011 г. Х. Клинтон в ходе своего визита в Индию огласила обновленную американскую стратегию Нового шелкового пути. Она была объявлена официальной политикой США в Южной Азии и одновременно направлена на решение проблем, оставленных войной в Афганистане. Американский проект «Новый шелковый путь» предполагает прохождение транспортных коридоров с юга на север, является вертикальной экономической полосой с центрами в Афганистане, Пакистане, Индии. Особая роль в нем отводится Афганистану как государству, имеющему удобное транспортное положение в Центральной Азии, - хабу, где связаны потоки человеческих и природных ресурсов.

Экономические маршруты Нового шелкового пути, разработанные американскими аналитическими центрами, такими как Институт Центральной Азии и Кавказа при университете Дж. Хопкинса, Центр стратегических и международных исследований, не подразумевают активного распространения американских цивилизационных ценностей в странах Центральной Азии. В их основе лежит идея о экономическом, а не цивилизационном противодействии другим акторам в Евразии [Кравченко 2016], о недопущении дальнейшего развития Евразии как суперконтинента (по аналогии с Северной Америкой, которая, благодаря строительству и запуску трансамериканской железной дороги, стала континентом двух океанов - Атлантического и Тихого [Calder 2019]).

Российское видение проекта Нового шелкового пути на протяжении длительного периода времени существенно не отличалось от того, что предлагала КНР. Это объясняется тем, что Россия долгое время не выдвигала ни одного альтернативного плана развития «пути», а только подтверждала свое участие в моделях, которые разрабатывал Пекин. Так, в 2015 г. на встрече глав двух государств было сделано заявление, в котором указывалось, что Россия «поддерживает строительство Экономического пояса Шелкового пути и готова к тесному взаимодействию с Китайской Стороной в продвижении этой инициативы» [Новый... 2016]. Это заявление стало продолжением инициатив отечественных ученых и

\footnotetext{
1 Central Asia Regional Economic Cooperation (CAREC) Program. 2019. URL: https://www.adb.org/ countries/subregional-programs/carec (accessed 24.04.2020).
} 
политиков, которые содержали предложения по интеграции в Шелковый путь Транссибирской и Байкало-Амурской магистралей. Кроме того, в рамках уже обозначенных КНР направлений Нового шелкового пути Россия предложила Ледовый шелковый путь [Михайличенко 2019: 339]. Он позиционировался как дополнительная возможность включения транспортной системы России в структуры «большого пути». При этом необходимо отметить, что цивилизационные механизмы обозначенных выше вариантов экономических интеграций не предлагались. Также не разрабатывались культурные подпроекты продвижения собственных цивилизационных ценностей в рамках Нового шелкового пути.

В отличие от Транссиба, БАМа, Ледового шелкового пути, развитие и модернизация которых позиционировались как составная часть китайского «большого проекта», еще одна российская инициатива - ТЕПР - рассматривалась в качестве его цивилизационной альтернативы. Она опиралась на следующие идеи: во-первых, «Россия - своеобразный интеграционный узел, связывающий Азию, Европу и Америку»1, во-вторых, «Россия не находится между Европой и Азией. Это Европа и Азия - слева и справа от России. Мы - не мост между ними, а отдельное цивилизационное пространство, где Россия объединяет цивилизационные сообщества Востока и Запада» 2 . На основе обозначенных идей предполагалось, что проект ТЕПР способен соединить Аляску и Лондон посредством создания транспортного моста через Берингов пролив. При этом экономический пояс Шелкового пути рассматривался в качестве одной из составных частей ТЕПРа. Согласно проектной задумке, России необходимо использовать свое геополитическое положение, стать центральным элементом в системе транспортных и энергетических интересов трех регионов - Западной Европы, Северной Америки, Юго-Восточной Азии. Для этого следует соединить порты Приморья и пограничные пункты путей Китая с западной границей Белоруссии, а затем спроектировать ответвление к Северной Америке через путь Сибирь-Берингов пролив-Аляска [Транс-Евразийский... 2014].

Как и в случае с Китаем, Россией и США, предложения Индии, связанные с формированием проектных контуров Нового шелкового пути, стали оформляться более 30 лет назад. Они предусматривали проектирование и строительство транспортных коридоров в обход Китая - транспортного коридора север-юг. Его целью являлась интенсификация экономических связей между Ираном, Россией, Кавказом и Центральной Азией. По оценкам экспертов, в экономическом отношении маршрут с севера на юг будет более многообещающим, чем некоторые возникающие в настоящее время сухопутные коридоры восток - запад ${ }^{3}$. Реализуя проектные задачи построения такого маршрута при минимальном привлечении дополнительных партнеров, Индия пытается все глубже проникнуть в инфраструктуру и экономику Евразии. Отказ от участия (2013 г.) в китайском проекте Нового шелкового пути подтвердил выбранный страной стратегический курс на реализацию собственного проекта «пути».

В дополнение к транспортному коридору север-юг, Индия принимает активное участие в развитии иранского порта Чабахар, грузооборот которого планируется увеличить в 5 раз. Кроме того, «Нью-Дели поддерживает строительство

1 Путин В.В. 2000. «Россия: новые восточные перспективы». Доступ: http://kremlin.ru/events/ president/transcripts/21132 (проверено 24.04.2020).

2 Владимир Якунин: на месте Транссиба создадим интегральную стратегическую базу развития России. Доступ: https://tass.ru/interviews/1599551 (проверено 24.04.2020).

3 Shepard W. 2017. Watch Out, China: India Is Building A «New Silk Road» of Its own. - Forbes. June. URL: https://www.forbes.com/sites/wadeshepard/2017/06/28/watch-out-china-india-is-building-a-newsilk-road-of-its-own/\#30d186d3a90e (accessed 24.04.2020). 
автомобильной дороги протяженностью 218 километров, связывающей центральную часть Афганистана с иранской границей, многосторонний проект “Каладан” в Мьянме, Трансазиатскую железную дорогу от Дакки до Стамбула, автомобильную магистраль Индия-Мьянма- Таиланд» 1 . Тем самым Индия показывает, что заинтересована в собственной модели развития Нового шелкового пути. В ее основе лежат экономические составляющие. Культурные же аспекты являются вторичными. Такое понимание Нового шелкового пути, с одной стороны, может позиционироваться в качестве конкурирующего с китайским проектным видением (особенно по линиям несовпадения цивилизационных ориентиров проектов). С другой стороны, китайская и индийская модели органично дополняют друг друга в создании масштабной транспортной сети всего евразийского пространства.

Таким образом, идентификация проектов Нового Шелкового пути имеет несколько моделей. Первая, цивилизационная, представлена проектными задумками и действиями КНР. Китай осуществляет попытки «синхронного продвижения» социокультурных и транспортных составляющих «пути». Официальный Пекин стремится возобновить социокультурные процессы, которые были характерны для Великого шелкового пути, а именно «переносы цивилизации» посредством языка, религии, валюты, экономического уклада и т.д. Вторая модель, суперконтинентальная, основана на проектных замыслах и действиях Индии. По многим параметрам (например, цивилизационное видение Нового шелкового пути) они являются взаимоисключающими. Однако «наложение» и «смешивание» некоторых параметров, особенно касающихся транспортного будущего «пути», формирует его новые контуры - «Евразия как суперконтинент», объединенный современной транспортной инфраструктурой, «Евразия как пространство», готовое бросить экономический вызов американскому «суперконтиненту». Третья модель, политическая, представлена проектными идеями и решениями США. Вашингтон, так же как Китай с Индией, предлагает разные модели видения Нового шелкового пути, но их объединяет преобладание в этих моделях политических составляющих над экономическими. Проектные задачи американских моделей слабо соотносятся с принципами экономической целесообразности, напротив, в них изначально заложены значительные риски и угрозы (центральная роль Афганистана как ключевого транспортного узла), которые могут помешать эффективной работе транспортной инфраструктуры. Думается, что современной России необходимо ориентироваться на цивилизационную модель проекта «Новый шелковый путь». Суперконтинентальные и политические модели этого мегапроекта имеют мощный конфликтный потенциал, который может не позволить Новому шелковому пути стать сложной, но эффективно работающей системой взаимодействия государств и народов.

\section{Список литературы}

Кравченко Л.И. 2016. «Новый Шелковый путь» - не экономика, а геополитика. Доступ: http://rusrand.ru/analytics/novyj-shelkovyj-put-ne-ekonomika-ageopolitika (проверено 24.04.2020).

Кузнецова Н.Ф. 2017. «Великий Шелковый путь» как способ интеграции объектов культурно-исторического наследия Южной Сибири в индустрию туризма. - Азимут научных исследований: экономика и управление. Т. 6. № 3(20). С. 219-224.

Михайличенко К.М. 2019. Проект «Ледовый Шелковый путь» в рамках ини-

1 Ibid. 
циативы «Один пояс и один путь» как реализация интересов России и Китая в Арктическом регионе. - Вестник Российского университета дружбы народов. № 2. С. 333-345.

Новый шелковый путь и евразийская интеграция. 2016. Доступ: https://www. geopolitica.ru/article/novyy-shelkovyy-put-i-evraziyskaya-integraciya (проверено 24.04.2020).

Сафранчук И. 2013. Концепция «Новый Шелковый путь» и политика США в «Большой Центральной Азии». - Междуннародная жизнь. № 7. С. 43-53.

Старр Ф. 2005. Партнерство для Центральной Азии. - Россия в глобальной политике. № 4. С. 159-166.

Тавровский Ю.В. 2017. Новый Шелковый путь. М.: Эксмо. 368 с.

Тулепбергенова Г. 2009. Проект Большой Центральной Азии: анализ состояния и эволюции. - Центральная Азия и Кавказ. № 1(61). С. 85-97.

Транс-Евразийский пояс «Razvitie». 2014. URL: http://www.kp-plant.ru/upload data/2015/TEDB-Razvitie.YakuninDoklad.pdf (проверено 24.04.2020).

Calder K. 2019. Super Continent. The Logic of Eurasian Integration. Stanford: Stanford University Press. 344 p.

Lee S. 2015. Establishment of Priority Relations of Interaction during the Implementation of the Initiative «One Belt, One Road». - Гоцзи изинизи пинлунь. № 1. P. 54-63.

Nisimura O. 2020. The Revival of the Eurasian Continent Will Radically Change the World. - Toyo Keizai online. January 19. Доступ: https://toyokeizai.net/articles/-/322306 (проверено 26.04.2020).

Starr F. 2009. Rediscovering Central Asia. URL: https://www.wilsonquarterly.com/ quarterly/summer-2009-thrift-the-double-edged-virtue/rediscovering-central-asia/ (accessed 24.04.2020).

VOLOBOEVA Yulia Konstantinovna, specialist of the Center for the Study of the Chinese Language (12 Novo-Kovalevo, St. Petersburg, Russia, 195043; voloboeva93@mail.ru).

GORBACHEV Mikhail Valer'evich, Dr.Sci. (Pol. Sci.), Associate Professor of the Chair of Russian Politics, Faculty of Political Science, Lomonosov Moscow State University (27 Lomonosovsky Ave, Moscow, Russia, 119192; ussr-86@mail.ru) YANG Min, Coordinator of Cultural and Educational Programs of the Tourist Complex of Xi'an (Jaifang/101, 101 Xi'an, China, 710048, aynmim3253454@126.com).

\section{THE NEW SILK ROAD PROJECT: BETWEEN CIVILIZATIONAL AND TRANSCONTINENTAL DIMENSIONS?}

\footnotetext{
Abstract. The article discusses options for identifying New Silk Road projects in India, China, the United States, and Russia. Based on the analysis, the authors identify their civilizational, supercontinent, and political versions. The article compares them and gives a description of their key characteristics. The article also emphasizes the stability and consistent implementation of civilizational models, criticizes political models, and casts doubt the possibility of implementing different variations of supercontinent models in the near future.
}

Keywords: Great Silk Road, New Silk Road, identification of New Silk Road projects 